

\title{
Theoretical Study of a High Permittivity Dielectric Resonator as a Potential NMR Probe
}

Marine Ac. Moussu, Elodie Georget, Redha Abdeddaim, Stefan Enoch, Stanislav Glybovski

\section{- To cite this version:}

Marine Ac. Moussu, Elodie Georget, Redha Abdeddaim, Stefan Enoch, Stanislav Glybovski. Theoretical Study of a High Permittivity Dielectric Resonator as a Potential NMR Probe. 2018 IEEE Radio and Antenna Days of the Indian Ocean (RADIO), Oct 2018, Wolmar, Mauritius. pp.1-3, 10.23919/RADIO.2018.8572301 . hal-02471917

\section{HAL Id: hal-02471917 https://hal.science/hal-02471917}

Submitted on 12 Mar 2020

HAL is a multi-disciplinary open access archive for the deposit and dissemination of scientific research documents, whether they are published or not. The documents may come from teaching and research institutions in France or abroad, or from public or private research centers.
L'archive ouverte pluridisciplinaire HAL, est destinée au dépôt et à la diffusion de documents scientifiques de niveau recherche, publiés ou non, émanant des établissements d'enseignement et de recherche français ou étrangers, des laboratoires publics ou privés. 


\section{Theoretical study of a high permittivity dielectric resonator as a potential NMR probe}

\author{
Marine AC. Moussu, Elodie Georget \\ Multiwave Innovation, 13453 \\ Marseille, France \\ marine@multiwave.fr
}

\author{
Redha Abdeddaim, Stefan Enoch \\ Aix Marseille Université, CNRS, \\ Centrale Marseille, Institut Fresnel, \\ UMR 7249, 13013 Marseille, France
}

\author{
Stanislav B. Glybovski \\ Department of Nanophotonics and \\ Metamaterials, ITMO University \\ St. Petersburg 197101, Russia
}

\begin{abstract}
In this short paper, we present a theoretical study of a new probe for Nuclear Magnetic Resonance (NMR) microscopy, based on high-permittivity and low-loss ceramic resonators. The probe design consists of two coupled annular resonators, with a maximum of axial magnetic field within them. An analytical study of the first transverse electric (TE) eigenmode of a single resonator was undertaken to assess the reliability of the magnetic field distribution for NMR imaging purposes. The developed analytical model also enabled to study coupling between resonators as a tool for tuning the probe at the Larmor frequency.
\end{abstract}

\section{INTRODUCTION}

Nuclear Magnetic Resonance (NMR) imaging requires the excitation of a sample with a radiofrequency magnetic field fulfilling two conditions: 1) orthogonal to the static magnetic field $B_{0}$ preconditioning the sample; 2) narrow-banded around the Larmor frequency imposed by $B_{0}$. Additionally, it should be as uniform as possible throughout the sample. The reference probe for NMR microscopy (i.e. imaging of tiny samples with sub-millimeter or micron resolution) is the solenoid: a constant current flowing along a metal wire generates a magnetic field mainly parallel to the solenoid axis, at least close to the axis [1]. It is tuned and matched at the Larmor frequency with capacitors while the sample is placed within the solenoid. The NMR solenoid probe has limited leeway in terms of design due to the trade-off between the homogeneity of the field and the Signalto-Noise Ratio (SNR) of the NMR response, that is mainly driven by intrinsic losses within the conductive wire [2], [3]. In response, the work [3] proposes a numerical study of a new probe for NMR microscopy at 17,2 $T$, based on two coupled annular-shaped, high permittivity dielectric resonators (DRs). Both the low-loss ceramics and the tuning to the Larmor frequency $f_{L}$ performed by adjusting the coupling between the two DRs ensure lower losses than in the case of the solenoid. In this paper, we investigate the theoretical background of such a resonant system and demonstrate the reliability of tuning the probe by electromagnetic coupling variation.

\section{SINGLE DIELECTRIC RESONATOR}

This section focuses on one element of the two coupled DRs probe described in [3].

\section{A. Model}

As a first approach, the annular-shaped dielectric resonator presented in [3], depicted in Fig. 1(a), is approximated as a plain

cylinder as in Fig. 1(b). Its properties are resumed in Table I. Reference [4] suggests indeed that the hole shifts slightly the resonant frequency but doesn't modify significantly the field distribution of the lowest-order eigenmode as far as the hole diameter $(5 \mathrm{~mm})$ is small enough compared to the external diameter of the cylinder $(18 \mathrm{~mm})$.

(a)

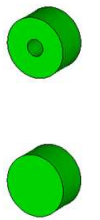

(c)



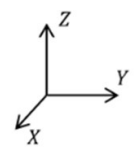

Fig. 1. Dielectric resonator: (a) Real resonator shape (annular); (b) Model shape (plain cylinder); (c) Notations for the DR model dimensions.

TABLE I. DR PROPERTIES

\begin{tabular}{c|c|c|c}
\multicolumn{2}{c|}{ Dimensions } & \multicolumn{2}{c}{ Electromagnetic properties } \\
\hline$L$ & $2 a$ & $\boldsymbol{\epsilon}_{\boldsymbol{r}}$ & $\tan \boldsymbol{\delta}$ \\
\hline $10 \mathrm{~mm}$ & $18 \mathrm{~mm}$ & 520 & $10^{-4}$
\end{tabular}

\section{B. $T E_{01}$ mode}

Due to the high value of the relative permittivity $\epsilon_{r}$, the electromagnetic field is mainly confined within the dielectric material [4], [5]. The resonant modes are then described while neglecting the field leakages at the lateral boundaries of the resonator (second order Cohn's model in [4]). The $T E_{01 \delta}$ mode is the lowest order eigenmode of a cylindrical resonator. As illustrated in Fig. 2, it is described by non-zero field components $H_{z}, H_{r}$ and $E_{\theta}$, and a cylindrical symmetry. The magnetic field generated in the center of the resonator is mainly axial, which is of interest for NMR probes.

\section{1) Resonant frequency estimation}

The resonant frequency $f_{r}$ is estimated as the average of an underestimate $f_{\min }$ of $f_{r}$ deduced from the second order Cohn's model [4] and an upper bound $f_{\text {max }}$ provided by an empirical expression derived in [6]. The computed value is $f_{r}=$ $753 \mathrm{MHz}$. An experimental measurement is performed on the annular resonator with a near-field probe (Langer EMVTechnik) and a vector network analyzer (Anritsu MS2027C). The result is $f_{r}^{\text {exp }}=750 \pm 5 \mathrm{MHz}$, while the targeted value at $17,2 \mathrm{~T}$ is $732,7 \mathrm{MHz}$. The estimated value is consistent with the 
actual resonant frequency of the resonator. However, fine tunability to the Larmor frequency is necessary for NMR imaging.

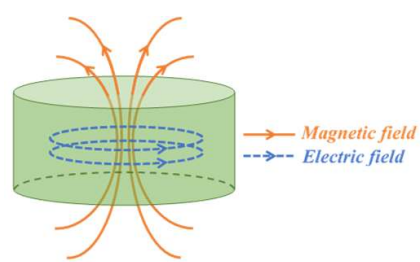

Fig. 2. $T E_{01 \delta}$ mode: electric and magnetic field lines [5].

\section{2) Field distribution}

The field distribution is estimated by applying the approach developed by J. Sheen in [7]: the DR is shielded by two conducting plates placed far enough so that they do not influence the mode [4]. The computed magnetic and electromagnetic fields are displayed in Fig. 3. The electric field low value region in the center of the resonator confirms the secondary impact of the hole on the resonant mode properties. (a)

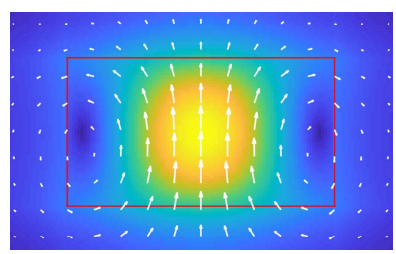

(b)

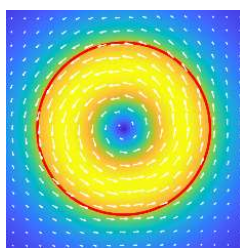

Fig. 3. (a) Magnetic and (b) Electric field distribution in the sagittal $(X Z)$ and transverse $(X Y)$ plane respectively.

\section{COUPLING OF $T E_{01 \delta}$ MODES OF TWO DIELECTRIC RESONATORS}

Coupling enables to tune the probe at the Larmor frequency by adjusting the axial shift $d$ between the two DRs (Fig. 4(a)), while the magnetic field distribution within the resonators (location of the sample) does not change significantly.

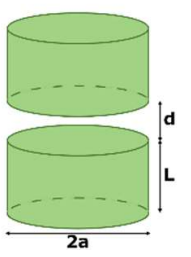

(a)

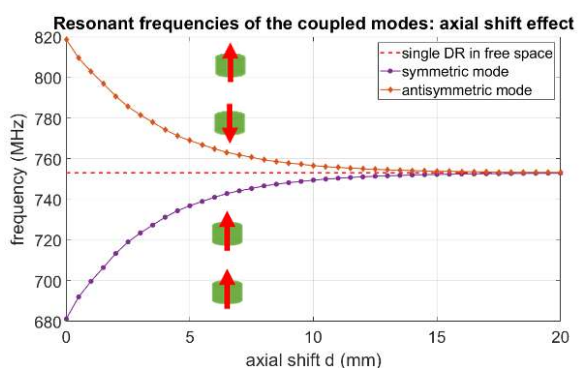

(b)
Fig. 4. Coupled modes frequencies versus distance between axially shifted DRs.

\section{A. Coupling theory}

Reference [8] resumes the coupling theory based on the spatial overlap of the initial modes field distribution. According to this work, in the case of two identical DRs shifted in a symmetric configuration, the coupling coefficient between two identical DRs is expressed as in (1) and the coupled modes, called symmetric or $(++)$ and antisymmetric or $(+-)$, are given in (2).

$$
\begin{gathered}
\kappa=\frac{\int \epsilon_{0}\left(\epsilon_{r}-1\right) \vec{E}_{1}^{*} \cdot \vec{E}_{2} d v}{\int \epsilon\left|\vec{E}_{1}\right|^{2} d v} \\
\left\{\begin{array}{l}
\vec{H}^{(++)}=\frac{1}{\sqrt{2}}\left(\vec{H}_{1}+\vec{H}_{2}\right), f^{(++)}=f_{r} \sqrt{1-|\kappa|} \\
\vec{H}^{(+-)}=\frac{1}{\sqrt{2}}\left(\vec{H}_{1}-\vec{H}_{2}\right), f^{(+-)}=f_{r} \sqrt{1+|\kappa|}
\end{array}\right.
\end{gathered}
$$

\section{B. Tunability of the two DRs probe: proof of feasibility}

The coupled modes frequencies are represented in Fig. 4(b). The Larmor frequency is accessible with the $(++)$ mode $\vec{H}^{(++)}$, described in Fig. 5, and $d \approx 4 \mathrm{~mm}$. (a)

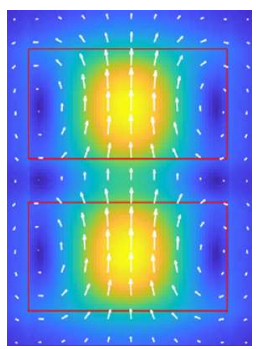

(b)
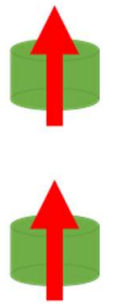

Fig. 5. $(++)$ coupled mode (computed from method in [7]): (a) Magnetic field distribution (sagittal plane); (b) schematic representation of the associated magnetic field.

\section{CONCLUSION}

This theoretical study proves that coupled high permittivity DRs fulfill the requirements on the magnetic field distribution and resonant frequency. Influence of laterally shifting the DRs has been currently investigated. Next step will be to consider the performances in terms of SNR and transmit power efficiency and compare it to the solenoid probe.

\section{REFERENCES}

[1] K. R. Minard and R. A. Wind. "Solenoidal microcoil design. Part I: optimizing RF homogeneity and coil dimensions." Concepts in Magnetic Resonance: An Educational Journal 13.2 (2001): 128-142.

[2] K. R. Minard and R. A. Wind. "Solenoidal microcoil design-Part II: Optimizing winding parameters for maximum signal - to - noise performance." Concepts in Magnetic Resonance Part A 13.3 (2001): 190210 .

[3] S. Kurdjumov, S. Glybovski et al. "A mechanically tunable and efficient ceramic probe for MR-microscopy at 17 Tesla.” AIP Conference Proceedings 2017 1874:1

[4] D. Kajfez and P. Guillon. "Dielectric resonators." Norwood, MA, Artech House, Inc., 1986, 547 p. (1986).

[5] A. G. Webb. "Dielectric materials in magnetic resonance." Concepts in magnetic resonance part A 38.4 (2011): 148-184.

[6] M. Rotaru and J. K. Sykulski. "Numerical investigation on compact multimode dielectric resonator antennas of very high permittivity." IET science, measurement \& technology 3.3 (2009): 217-228.

[7] J. Sheen. "A dielectric resonator method of measuring dielectric properties of low loss materials in the microwave region." Measurement Science and Technology 19.5 (2008): 055701.

[8] I. Awai and Z. Zhang. "New expression of coupling coefficient between resonators based on overlap integral of EM field." Microwave Conference Proceedings, 2005. APMC 2005. Asia-Pacific Conference Proceedings. Vol. 4. IEEE, 2005. 